University of Innsbruck

Working Papers in Economics and Statistics

The series is jointly edited and published by

- Department of Banking and Finance

- Department of Economics

- Department of Public Finance

- Department of Statistics

Contact address of the editor:

research platform "Empirical and Experimental Economics"

University of Innsbruck

Universitaetsstrasse 15

A-6020 Innsbruck

Austria

Tel: $\quad+4351250771022$

Fax: $\quad+435125072970$

E-mail: eeecon@uibk.ac.at

The most recent version of all working papers can be downloaded at https://www.uibk.ac.at/eeecon/wopec/

For a list of recent papers see the backpages of this paper. 


\title{
Trust in health care credence goods: Experimental evidence on framing and subject pool effects $^{*}$
}

\author{
Silvia Angerer ${ }^{\star}$, Daniela Glätzle-Rützler ${ }^{*}$, and Christian Waibel ${ }^{\dagger}$
}

\begin{abstract}
Credence goods markets are characterized by asymmetric information concerning the needed and/or provided quality between experts and consumers. The functioning of the market heavily relies on trust on the side of the consumer as well as trustworthiness on the side of the expert. However, a great amount of empirical and experimental papers document for a range of different credence goods markets the existence of over-, undertreatment, and overcharging. In this paper, we study two determinants of trust and trustworthiness in experimental credence goods markets, namely the effect of a health frame (versus a neutral frame) as well as the identity of the expert (being either a standard student subject or a prospective physician). Our results reveal that the identity in combination with a health frame has a significant impact on the level of trust shown by a higher willingness of consumers (patients) to enter the market. Trustworthiness, as measured by the provision and charging behavior of experts, however, is not significantly influenced by the health care framing, nor by the subject pool.
\end{abstract}

JEL-Codes: C91, D82, I11

Keywords: Health care economics, trust, fraud, framing effects, experts, credence goods, undertreatment, overcharging, laboratory experiment

Date: $\quad$ March 4, 2021

Competing interests statement: The authors have no competing interests

\footnotetext{
*Funding: This work was supported by the Nachwuchsförderung at the University of Innsbruck; and the Austrian Central Bank [grant number 17805]

${ }^{\&}$ UMIT - Private University for Health Sciences, Medical Informatics and Technology, Institute for Management and Economics in Healthcare, Eduard-Wallnöfer-Zentrum 1, 6060 Hall in Tirol, Austria. silvia.angerer@umit.at.

${ }^{*}$ Corresponding Author, University of Innsbruck, Universitätsstrasse 15, 6020 Innsbruck, Austria. daniela.ruetzler@uibk.ac.at.

${ }^{\dagger}$ ETH Zurich, Zuerichbergstrasse 18, 8092 Zurich, Switzerland. cwaibel@ethz.ch.
} 


\section{Introduction}

Trust is a key aspect in markets for credence goods, characterized by information asymmetries between providers and consumers. Compared to other goods, where consumers typically learn the quality of goods during or after consumption, the quality of credence goods may even after consumption be difficult to assess (Darby and Karni, 1973; Dulleck and Kerschbamer, 2006; Nelson, 1970). Hence, providers are experts and may exploit their informational advantage in different ways: An expert may either provide more services than necessary (overtreatment), fewer services than necessary (undertreatment), or the appropriate service but charge for a higher price (overcharging) (Dulleck and Kerschbamer, 2006). Thus, the consumer has to trust the expert that he or she provides the appropriate service and charges the correct price.

Empirical evidence for all three types of unethical behavior has been shown in different credence goods markets, including the market for taxi rides (Balafoutas et al., 2013; Balafoutas et al., 2017), computer specialists (Kerschbamer et al., 2016), auto repair services (Rasch and Waibel, 2018; Schneider, 2012) and health care (Clemens and Gottlieb, 2014; Cutler, 1995; Gottschalk et al., 2020; Jürges and Köberlein, 2015; Pasero and McCaffery, 2001). ${ }^{3}$ Despite the spread of unethical behavior over different contexts, the extent of fraud may be different depending on the market under investigation.

In health care markets, experts are subject to particularly high ethical standards by virtue of the Hippocratic ideals all physicians subscribe to. Therefore, physicians should be expected to be more trustworthy than experts in other credence goods markets. Physicians' trustworthiness is also underlined by the Gallup poll on the rating of the honesty and ethical standards of people in different professions where medical doctors outperform most other professions, including bankers, lawyers, or car salespeople (Brenan, 2018). Since trust involves beliefs about the trustworthiness of a party, consumers (patients) in a health care market are expected to trust physicians more than other experts. We aim to test this research hypothesis in our paper using a credence goods framework. ${ }^{4}$

Experimental studies investigating the effect of a health framing and the use of a naturalistic subject pool such as medical students or physicians compared to standard subject pools show that a health frame and the subject pool has an impact on medical decision making in a laboratory setting (Ahlert et al., 2012; Ahlert et al., 2013; Brosig-Koch et al., 2016; Cox et al., 2016; Hennig-Schmidt

\footnotetext{
${ }^{3}$ Even though in most health systems prices are regulated, overcharging is still a prevalent phenomenon in the hospital setting with a DRG-based reimbursement system (Hennig-Schmidt et al., 2019; Jürges and Köberlein, 2015).

${ }^{4}$ While the trust game more directly measures trust and trustworthiness, the credence goods framework is better suited to model the information asymmetry between patients and physicians in health care markets (Balafoutas and Kerschbamer, 2020; Huck et al., 2016). Given the informational advantage of physicians and the possibility that physicians might mistreat patients, market efficiency is determined by the amount of trust (and trustworthiness) in the market (for a discussion of trust in the medical marketplace see Maynard and Bloor, 2003). Piette et al. (2005) show that when patients' trust in their physicians is low they are more likely to forgo medications because of cost preassure than when trust levels are high. Of course there might be other motivations for patients' interaction with doctors, like urgent need for treatment.
} 
and Wiesen, 2014; Kesternich et al., 2015; Reif et al., 2020). However, to date, to the best of our knowledge, there exists no study investigating the impact on patient decision making and thus measuring the level of trust in a healthcare market.

In this paper, we use a credence goods model to analyze whether a health care framing and the identity of the expert has an impact on the level of trust of consumers in a credence goods market. More specifically, we implement the experimental design of Dulleck et al. (2011) and extend their baseline treatment by two further experimental conditions. In one condition, we introduce a health care framing with a conventional subject pool in order to investigate the impact of the health care context on the level of trust by consumers, i.e. patients, and on expert behavior, i.e. physicians. In a second variation, we additionally introduce medical students in the role of physicians, which allows us to study the impact of the identity of experts on the level of trust by students in the role of patients and to measure the trustworthiness of real experts in a more naturalistic setting.

Our results suggest that the identity in combination with a health care context has a significant impact on the level of trust, as shown by the frequency of market entry by consumers (patients) and thus the interaction rate between experts (physicians) and consumers (patients). In the condition with a health care setting and medical students in the role of physicians, the interaction rate increases by 20 percentage points to a level of $65 \%$ compared to a level of $45 \%$ in the baseline condition. However, the behavior of experts is not significantly influenced by the health care framing, nor by their identity (being either a standard student subject or a prospective physician). Thus, even though the level of trust is significantly higher towards medical students in the context of a health care market, the level of trustworthiness does not differ significantly between conditions.

The role of framing and the subject pool has been investigated in various laboratory experiments. ${ }^{5}$ In the following, we will concentrate on the studies most closely related to the underlying research question. In the context of credence goods experiments, Beck et al. (2014) investigate the behavior of professional car mechanics in an experimental credence goods market and compare it to the behavior of a standard student subject pool. They find very similar behavioral responses - except for the level of overtreatment, which is higher among car mechanics. In a health care context, the behavior of standard student subjects, medical students, and physicians was compared by Brosig-Koch et al. (2016). In their study, the effect of different payment schemes (fee-for-service vs. capitation) on the provision of medical services in a laboratory experiment framed in a physician decision-making situation was analyzed. The results suggest that all three subject pools react consistently towards financial incentives and provide more medical services under fee-for-service than under capitation. However, physicians react less towards financial incentives than medical and non-medical students. In an earlier study Hennig-Schmidt and Wiesen (2014) compare medical students with non-medical students in a similar setting showing that medical students are more patient-regarding and thus willing

\footnotetext{
${ }^{5}$ See, for instance, the seminal paper by Tversky and Kahneman (1981) or the experimental investigation of framing and subject pool effects in the trust game (Chaudhuri et al., 2016), in public goods games (Cookson, 2000; Dufwenberg et al., 2011) and in the prisoner’s dilemma game (Goerg and Walkowitz, 2010).
} 
to sacrifice more from their own profit than non-medical students, regardless of the payment scheme (fee-for-service or capitation). ${ }^{6}$ In line with these results, Ahlert et al. (2012, 2013) also provide evidence that in a neutral and a medical framed allocation task, prospective economists are more selfish than prospective physicians. Concerning the framing of the task, they find that professional norms influence decision making with economists moving further away from selfishness in a medical context. Kesternich et al. (2015) employ a simple distribution task providing additional evidence on framing effects. They manipulate in their study the salience of professional norms (i.e. Hippocratic Oath reminder versus no reminder), the framing (neutral versus medical framing), as well as the identity of the recipient (student versus real-world charity caring for patients). While the provision of the good is on average, not higher in a medical framing, it significantly increases when the receiver is a charity. Moreover, the salience of professional norms decreases the selfishness of their (medical student) subjects but only in the medical framing. Using a patient-physician-insurance model, Reif et al. (2020) also investigate the effect of a medical framing and the subject pool on medical decision making in a laboratory experiment. They show that medical doctors behave similarly to students and that a health framing increases patient-regarding behavior. The effect of a health framing on decision quality for health insurance choices based on individual cumulative prospect theory was analyzed in Kairies-Schwarz et al. (2017). Their results show that the health framing improves significantly the decision quality resulting in a fewer number of inconsistent choice patterns compared to a neutral framing. Using a political economy model to investigate the decision to exit from public to private finance, Buckley et al. (2016) also investigate framing effects between a neutrally and a medically framed decision situation. They find a significant difference between the two frames with the proportions of exits being significantly higher in a health-frame than in a neutral-frame. ${ }^{7}$

Given the evidence on the difference in the behavior of health care providers to providers in other economic sectors, our study addresses an important topic in experimental health economics (Cox et al., 2016) and contributes to this strand of the literature on two key dimensions. First, compared to the studies investigating the effect of a naturalistic framing and subject pool on medical decision making (Ahlert et al., 2012; Ahlert et al., 2013; Brosig-Koch et al., 2016; Hennig-Schmidt and Wiesen, 2014; Kesternich et al., 2015; Reif et al., 2020) where patients have a passive role and therefore are not present in the laboratory, a credence goods model allows the investigation of both sides of the market - experts and consumers. Second, by using a credence goods setting, we also contribute to the literature on credence goods. While there exist different studies using a credence goods model with a focus on the healthcare market (Angerer et al., 2021; Huck et al., 2016; Mimra et al., 2016a, b), non of

\footnotetext{
${ }^{6}$ Wang et al. (2020) study subject pool effects across countries in a similar setting as the previous two studies and find a remarable stability in patient-regarding preferences when comparing the behavior of Chinese medical doctors, German medical students and Chinese medical students.

${ }^{7}$ Even though both studies (Buckley et al., 2016; Kairies-Schwarz et al., 2017) investigate framing effects on the demand side of a health market (the insurance demand), the papers are not directly related to our paper, since the focus is on health insurance decisions and not on the behavior of patients and physicians in a physician-patient interaction.
} 
these studies investigate the effect of a health framing compared to a neutral framing. Our study, thus, provides the first experimental evidence of the effect of a health framing and the use of prospective physicians as experts on market efficiency as well as expert and consumer behavior in a credence goods setting.

In line with the research hypothesis, our study shows that trust in health care markets as shown by the frequency of student subjects in the role of patients interacting with prospective physicians is higher than for a neutrally framed credence goods market with standard student subjects in the role of the expert. However, we find no (significant) support for an increased level of trustworthiness. In the following, we introduce the conceptual framework and the experimental design in section 2. The results are presented in section 3. Section 4 provides a discussion of our results and concludes the paper.

\section{Material and Methods}

The research design is based on the credence goods model proposed by Dulleck and Kerschbamer (2006) and the experiment implemented by Dulleck et al. (2011) in which the authors test the institutions of liability, verifiability, competition, and reputation to solve the problems associated with the information asymmetry in a credence goods market. We use the data from their baseline condition and extend the design to answer our research questions. ${ }^{8}$

In the following, we briefly present the structure of the baseline model, described in detail in Dulleck et al. (2011), the experimental conditions, the procedure, and our research questions together with the hypotheses.

\subsection{Basic Set-up and Parameters}

The credence goods set-up consists of two parties, the expert (he) and the consumer (she). Experts can provide two types of goods, a high-quality good $\left(q^{h}\right)$ with the costs of $c^{h}=6$ or a low-quality good $\left(q^{l}\right)$ with the costs of $c^{l}=2$. All consumers need either a high or a low quality good, each with an equal probability of $50 \%$. The probability is common knowledge, however, in the respective period consumers are not informed about the type of quality they need. A consumer is served sufficiently in case she needs $q^{l}$, independent from the type of quality provided, or in case she needs $q^{h}$ and receives $q^{h}$. Experts learn the quality needed by a consumer with certainty. The expert at the beginning of each period sets two types of prices, $p^{h}$ for the high quality good and $p^{l}$ for the low-quality good (with $1 \leq p^{l} \leq p^{h} \leq 11$ ). However, the expert can decide independently from the chosen quality, whether

\footnotetext{
${ }^{8}$ The data is available online at https://www.aeaweb.org/articles?id=10.1257/aer.101.2.526. Note that even though the data was collected before 2011, Camerer et al. (2016) were able to replicate the results of Dulleck et al. (2011) in their evaluation of the replicability of laboratory experiments in economics. Given the replicability, the fact that we are running the experiments in the same location/laboratory, and the limited ressources available for research, we decided to refrain from re-collecting the baseline data.
} 
to charge $p^{h}$ or $p^{l}$. A consumer is randomly matched with an expert and can decide whether to interact with the expert or to stay out of the market. The only information the consumer receives before deciding to interact with an expert is the menu of prices the randomly matched expert charges for both types of qualities (see Figure A1 in the Appendix for a representation of the stage game in the extensive form).

In case of interaction, the payoffs are the following. The expert receives $p_{i}-c_{j}$ (with $i \in(h, l)$ and $j \in(h, l)$ ) and the consumer receives the value of the provided quality $(v)$ minus the price charged by the expert. The value depends on whether the quality received was sufficient $(v=10)$ or not $(v=0)$. In the case of no interaction, the payoff is 1.6 for both the expert and the consumer.

The stage game of the baseline set-up is the following:

1. For each consumer, nature draws the type of quality needed. With $50 \%$ probability the consumer needs $q^{h}$, and with 50\% probability the consumer needs $q^{l}$.

2. The expert posts prices $p^{h}$ and $p^{l}$ with $1 \leq p^{l} \leq p^{h} \leq 11$.

3. The consumer is informed about the prices $p^{h}$ and $p^{l}$ the randomly matched expert charges and decides whether to interact or not. If the consumer decides not to interact with the expert, the period ends. Otherwise:

4. The expert is informed about the quality needed and provides $q^{h}$ or $q^{l}$ and charges $p^{h}$ or $p^{l}$.

5. Each consumer observes her payoff, and each expert observes his payoff.

\subsection{Experimental Conditions}

The basic set-up described in the previous section represents the baseline condition $\boldsymbol{B}$ which was explained in a neutral framing with experts being player A and consumers being player B. Experts can choose between two actions, action I $\left(q^{l}\right)$ and action II $\left(q^{h}\right)$, and the prices for both actions. The subjects participating in the experiment were standard students, primarily economic and business students. In the two experimental conditions, we introduce the following variations. First, in condition $\boldsymbol{H F}$ we introduce a health framing with experts being in the role of physicians and consumers in the role of patients. Each patient has a mild or severe health problem which can be cured with the mild treatment $q^{l}$ or the severe treatment $q^{h}$. Subjects participating in this experiment were again standard student subjects, primarily economic and business students. In our second variation, HF\&MS, we again use a health frame but now with medical students in the role of physicians. Patients were again standard student subjects, primarily economic and business students (see Table 1 for an overview of the experimental conditions). ${ }^{9}$

\footnotetext{
${ }^{9}$ Note that for a systematic $2 \times 2$ design a condition looking at the effect of medical students in the role of experts with a neutral frame is missing (B\&MS). However, since the experiment is motivated by investigating trust and trustworthiness in a health care credence goods market compared to a neutrally framed credence goods market, a condition with medical students in the role of experts coupled with a neutral frame is an unnatural setting.
} 
Table 1: Experimental conditions

\begin{tabular}{lccccc}
\hline & Frame & $\begin{array}{c}\text { Description } \\
\text { Experts }\end{array}$ & Consumers & \# sessions & $\begin{array}{c}\text { \# markets } \\
\text { (\# subjects) }\end{array}$ \\
\hline $\boldsymbol{B}$ & Neutral & Standard students & Standard students & 4 & $12(96)$ \\
HF & Health & Standard students & Standard students & 3 & $9(72)$ \\
HF\&MS & Health & Medical students & Standard students & 4 & $10(80)$ \\
\hline TOTAL & & & & 11 & $31(248)$ \\
\hline
\end{tabular}

\subsection{Experimental Protocol}

The stage game is repeated for 16 periods. Subjects are randomly assigned either the role of the expert (physician) or the consumer (patient) at the beginning of the experiment, except for condition HF\&MS, where all medical students are assigned the role of the physician and all other invited participants are in the role of the patient. Besides, all subjects are randomly matched within a group of 4 experts (physicians) and 4 consumers (patients). Within this matching group of 8 subjects, each anonymous consumer (patient) is randomly matched with an anonymous expert (physician) in each period. Ultimately, four periods are randomly selected to determine participant payments.

Both data collections were conducted at the laboratory for experimental economic research at the University of Innsbruck with a total of 248 subjects, 96 in the experiment from Dulleck et al. (2011) and 152 in the underlying experiment (see Table 1 for an overview of sessions, markets, and subjects for each experimental condition). The experiment was computerized using zTree (Fischbacher, 2007), and students were recruited using hroot (Bock et al., 2014). ${ }^{10}$ Moreover, the study was approved by the internal review board of the University of Innsbruck. Following the protocol used in Dulleck et al. (2011) all subjects were instructed to read a detailed description of the game and to answer a set of control questions that were incentivized to give each subject an initial endowment designed to offset any resulting negative period profits (see the instructions and control questions in the Appendix). At the end of the session, subjects in our two conditions were additionally asked to fill out a short postexperimental questionnaire on socio-demographic background information (gender, age, studies, and semester; see Table A1 in the Appendix for the descriptive statistics). This information is not available for condition $\boldsymbol{B}$. The questionnaire, however, was announced at the end of the session to exclude any potential influence of the data collection on the behavior of subjects in our experiment.

Further, through the possility of students inferring a health setting from this unnatural instruction, the interpretation of this condition (B\&MS) compared to the condition with a health frame (HF\&MS) is ambiguous. ${ }^{10}$ Students who had previously participated in a credence goods game more than twice were excluded from the pool of subjects as well as medical students in condition $\boldsymbol{H F}$. 


\subsection{Research Questions and Hypotheses}

The experimental design allows answering the following research questions.

1. Expert (physician) behavior:

i. What is the impact of a health framing on expert behavior in a credence goods setting?

ii. Does the expert behavior of prospective physicians differ from standard student subjects in the role of physicians in a credence goods setting?

2. Consumer (patient) behavior: What is the impact of (i) a health framing and (ii) the use of prospective physicians in the role of physicians on consumer (patient) behavior in a credence goods setting?

3. Market efficiency: What is the impact of (i) a health framing and (ii) the use of prospective physicians in the role of physicians on market efficiency in a credence goods setting?

Assuming rationality of market participants, risk neutrality and utility functions that depend only on the monetary payoffs of decision makers, the theoretical predictions for the stage game in the three experimental conditions provide a unique Perfect Bayesian Nash equilibrium in which experts always provide the low quality and charge the price for the high quality good. Anticipating the behavior of experts, consumers do not interact with the expert and thus the market breaks down. The results from Dulleck et al. (2011) show that the market does not break down. However, there is a significant amount of undertreatment (53\%) and overcharging (81\%) and only $45 \%$ of consumers interact with an expert. Given the results from previous literature on the effect of health framing and the subject pool on medical decision making (Ahlert et al., 2012; Ahlert et al., 2013; Brosig-Koch et al., 2016; HennigSchmidt and Wiesen, 2014; Reif et al., 2020), we propose the following hypotheses concerning the behavior of subjects in the role of physicians. ${ }^{11}$

\section{Hypotheses 1: Expert (physician) behavior}

1a $(\boldsymbol{H F}$ vs. $\boldsymbol{B})$ : Both, the level of undertreatment and overcharging is lower with a health frame than without a health frame.

1b (HF\&MS vs. HF): Both, the level of undertreatment and overcharging is lower when prospective physicians are in the role of physicians than with standard student subjects.

Given our expectations on the higher amount of trustworthiness for subjects in the role of physicians in both $\boldsymbol{H F}$ and $\boldsymbol{H F \& M S}$, we expect subjects in the role of patients to show a higher level of trust and thus to interact more often.

\footnotetext{
${ }^{11}$ Note, however, that Kesternich et al. (2015) don't find a significant impact of a health framing on medical decision making in their setting and that Reif et al. (2020) do not find a difference between medical doctors and non-medical students.
} 


\section{Hypotheses 2: Consumer (patient) behavior}

2a $(\boldsymbol{H F}$ vs. $\boldsymbol{B})$ : The frequency of market interaction between patients and physicians is higher with a health frame than without a health frame.

2b (HF\&MS vs. HF): The frequency of market interaction between patients and physicians is higher when prospective physicians are in the role of physicians than with standard student subjects.

Combining the previous hypotheses on expert behavior and consumer behavior leads to the following hypotheses concerning the level of market efficiency, measured as the sum of patient and physician surplus divided by the maximum possible market surplus.

\section{Hypotheses 3: Market efficiency}

3a (HF vs. B): The level of market efficiency is higher with a health frame than without a health frame.

3b (HF\&MS vs. HF): The level of market efficiency is higher when prospective physicians are in the role of physicians than with standard student subjects.

From our hypotheses, we can derive the following ordering for the expected expert (physician) behavior, consumer (patient) behavior, and market efficiency concerning our three experimental conditions.

1. Expert (physician) behavior, i.e. undertreatment and overcharging: $\boldsymbol{H F} \& \boldsymbol{M S}<\boldsymbol{H F}<\boldsymbol{B}$

2. Consumer (patient) behavior, i.e. interaction rate: $\boldsymbol{H F} \boldsymbol{Q} \boldsymbol{M S}>\boldsymbol{H F}>\boldsymbol{B}$

3. Market efficiency, i.e. the sum of consumer (patient) and expert (physician) surplus: HF\&MS $>$ HF $>B$

\section{Results}

In this section we provide an overview of our main outcome and decision variables for each of the three experimental conditions, discuss dynamics over periods and differences between conditions to answer our research questions. Table 2 displays the results shown in Dulleck et al. (2011) for the baseline condition $\boldsymbol{B}$ in column two and columns three and four provide the results averaged over periods from $\boldsymbol{H F}$ respectively $\boldsymbol{H F} \boldsymbol{M} \boldsymbol{M S}$. Table 3 provides the results from random effects probit regressions for the differences between the three experimental conditions. 
Result 2 (patient/consumer behavior): The frequency of interactions between patients and physicians is significantly higher for the health framing with medical students in the role of physicians compared to the baseline condition. This is due to the combination of a health framing and medical students in the role of physicians. The framing alone has a marginally significant effect on the interaction rate and the isolated effect of the medical students compared to the health framing with standard students shows no statistically significant difference in the frequency of market interactions.

The analysis of the interaction rate between consumers and experts, and thus the level of trust of consumers, shows the expected ordering between treatments with the least amount of trust in the baseline condition (45\%), followed by a health care setting (57\%) and highest in a health care setting with medical students in the role of physicians (65\%). This difference is significant at the $10 \%$ level for the health framing compared to the baseline condition (as shown by the first coefficient in regression model 3 of Table 3) and at the 1\% level for $\boldsymbol{H F \& M S}$ compared to the baseline condition (as shown by the second coefficient in regression model 3 of Table 3). The binary comparison between $\boldsymbol{H F}$ and $\boldsymbol{H F} \boldsymbol{Q} \boldsymbol{M S}$ shows no statistically significant difference (see p-value from the Wald-test below regression model 3 of Table 3).

Result 3 (market efficiency): The market efficiency in the health framing with and without medical students in the role of physicians is not significantly different from the baseline condition.

When comparing the level of market efficiency, we do not find support for hypotheses 3a and 3b, even though the ordering between conditions is as expected. However, the difference between the three conditions is not statistically significant (see coefficients and p-values of the first two independent variables and the post-estimation Wald test of regression model 4 in Table 3).

Table 3: Random effects panel probit / OLS

\begin{tabular}{lcccc}
\hline \multirow{2}{*}{ VARIABLES } & $(1)$ & $(2)$ & $(3)$ & $(4)$ \\
& $\mathrm{OC}^{1, \mathrm{a}}$ & $\mathrm{UT}^{2, \mathrm{a}}$ & $\mathrm{INT}^{3, \mathrm{a}}$ & $\mathrm{EFF}^{4, \mathrm{~b}}$ \\
\hline \multirow{3}{*}{ HF $(=1)$} & & & & \\
& -0.367 & -0.316 & $0.411^{*}$ & 0.055 \\
HF\&MS (=1) & $(0.705)$ & $(0.828)$ & $(0.236)$ & $(0.202)$ \\
& -0.431 & -0.961 & $0.657^{* * *}$ & 0.255 \\
Period & $(0.608)$ & $(0.803)$ & $(0.203)$ & $(0.172)$ \\
& $0.116^{* * *}$ & $0.108^{* * *}$ & $-0.055^{* * *}$ & 0.001 \\
Constant & $(0.031)$ & $(0.023)$ & $(0.009)$ & $(0.010)$ \\
& $1.252^{* *}$ & -0.580 & $0.295^{* * *}$ & $-0.461^{* * *}$ \\
& $(0.569)$ & $(0.477)$ & $(0.082)$ & $(0.146)$ \\
Observations & & & & \\
Number of subjectid & 578 & 511 & 1,984 & 1,984 \\
\hline
\end{tabular}




\footnotetext{
Wald test (p-values)

$H_{0}: \beta_{H F}=\beta_{H F \& M S}$

0.938

0.480

0.405

0.382

Notes: $* * * \mathrm{p}<0.01,{ }^{* *} \mathrm{p}<0.05,{ }^{*} \mathrm{p}<0.1$

${ }^{1}$ Overcharching (OC): seller provides $q_{l}$, but charges $p_{h}$ (with $p_{h}>p_{l}$ and consumer needing $q_{l}$ )

${ }^{2}$ Undertreatment (UT): consumer needs $q_{h}$, but the seller provides $q_{l}$

${ }^{3}$ Relative frequency of market interaction (INT)

${ }^{4}$ Market efficiency (EFF) calculated as $\frac{\text { actual average profit }}{\text { maximum possible profit }}$

${ }^{\text {a }}$ Random effects panel probit with robust standard errors clustered on the matching group level in parentheses

${ }^{\mathrm{b}}$ Random effects panel OLS with robust standard errors clustered on the matching group level in parentheses
}

Figure 1 shows the development of our main outcome variables over the 16 periods for our three experimental conditions. Panel D shows that the interaction rate significantly decreases throughout the 16 periods. Nevertheless, the difference in the interaction rate between our conditions persists throughout the 16 periods for all three conditions. Besides, also panels B and C show a significant increase in the level of undertreatment and overcharging, except for condition $\boldsymbol{H F}$. No dynamic trends are found for market efficiency (see also the coefficients for the variable "period" in Table 3 as well as Table A2 in the Appendix for the analysis of period effects for each condition separately).

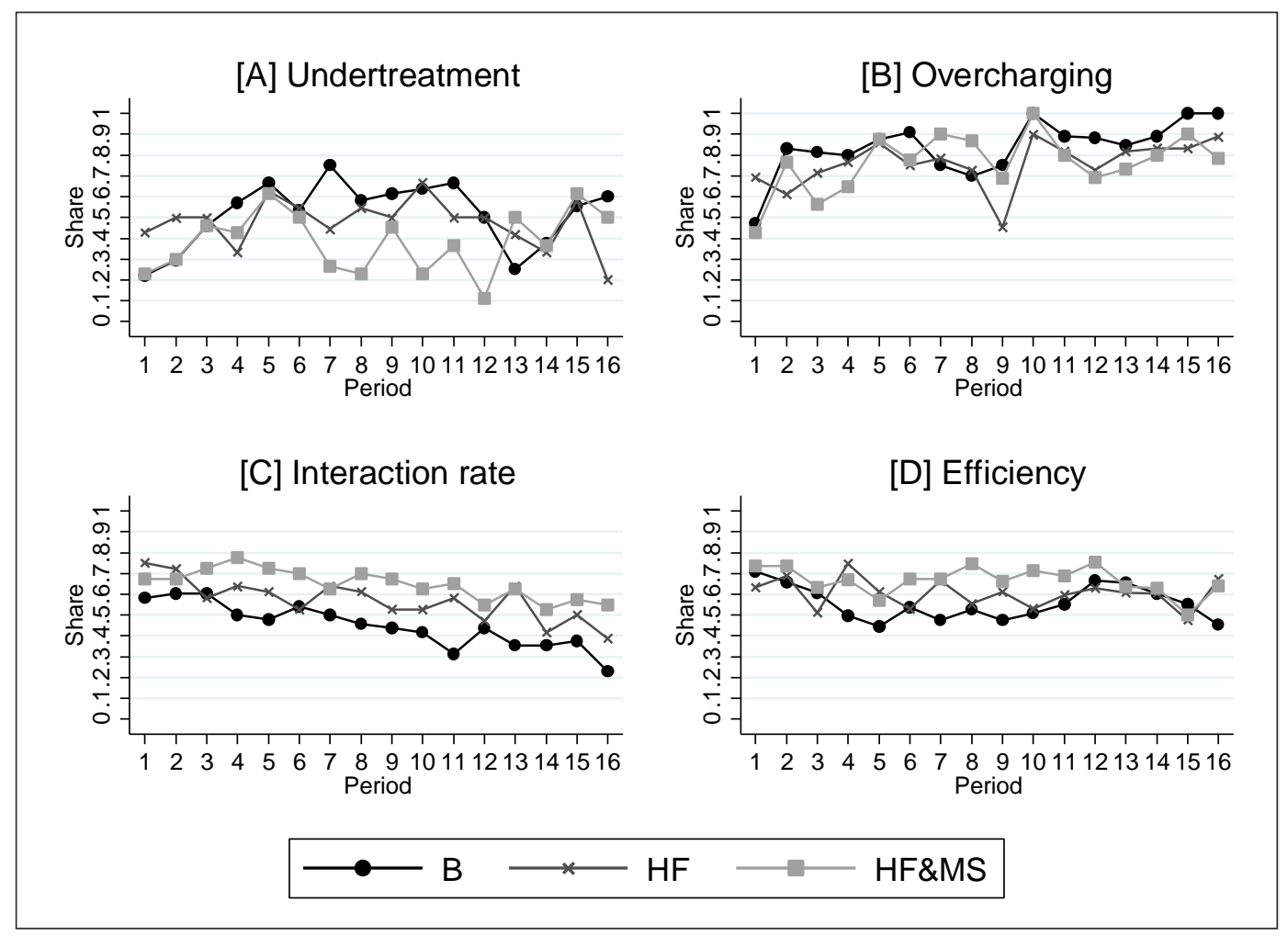

Figure 1: Provision, charging, market interaction, and efficiency across rounds by conditions $\boldsymbol{B}, \boldsymbol{H F}$ and $\mathbf{H F} \& \boldsymbol{M S}$ 


\section{Discussion and conclusion}

We analyze the impact of a health framing and the use of prospective physicians in the role of experts in a credence good setting on the level of trust, trustworthiness, and the resulting market efficiency compared to a neutrally framed market with standard student subjects in the role of experts.

In line with our hypothesis, we find a significant increase in the level of trust, measured as the frequency of market interactions between patients and physicians. In a health care setting with prospective physicians in the role of experts, the interaction rate increases by 20 percentage points to a level of $65 \%$ compared to a neutrally framed setting with standard students in the role of experts. However, even though the average frequency of undertreatment and overcharging decreases in the health care setting with medical students in the role of experts, the reduction is not significant due to a high variance in expert behavior. Also for market efficiency, the results point towards the expected direction of an increase, however, the difference between the experimental conditions is not significant. Given that the expert behavior does not differ significantly between conditions, the increased level of trust by subjects in the role of patients can be ascribed to the partially wrong expectations about the higher level of trustworthiness of experts in the role of physicians and does not reflect the reactions to the real experience from their market interactions.

The null result of the effect of health framing and medical students in the role of physicians on expert behavior in our setting does not conform to some results from previous experiments investigating the effect of health framing and the subject pool on medical decision making (Ahlert et al., 2012; Ahlert et al., 2013; Brosig-Koch et al., 2016; Hennig-Schmidt and Wiesen, 2014). ${ }^{14}$ This can be due to two important differences.

First, in the other experiments, the authors use an individual allocation task where only subjects in the role of physicians make a decision. In our setting, due to our primary research question, also subjects in the role of patients make decisions and thus the behavior of physicians (experts) also depends on the beliefs of the behavior of future patients. Given the fact that a significant proportion of subjects in the role of patients does not interact (even though the interaction rate increases in condition $\boldsymbol{H F}$ and $\boldsymbol{H F} \& \boldsymbol{M S}$ ), there might be a stronger strain to subjects in the role of experts in our study to guarantee an adequate profit at the end of the experiment and thus engage in the same level of undertreatment and overcharging as in the baseline condition. An avenue for future research could be to investigate the impact of a health framing on physician behavior in a credence goods market with competition and reputation where Dulleck et al. (2011) show that the level of trade and thus the interaction frequency increases significantly compared to the baseline condition.

Besides, compared to Brosig-Koch et al. (2016) and Hennig-Schmidt and Wiesen (2014), patients in our setting are standard student subjects participating in experiments, and the health benefits generated by experts in the health care frame are translated into money paid to the subjects in the role

\footnotetext{
${ }^{14}$ In line with our results, Kesternich et al. (2015) also don't find a significant impact of a health framing on medical decision making in their setting. Also Reif et al. (2020), even though finding an impact of health framing do not find an effect of the subject pool.
} 
of patients. Brosig-Koch et al. (2016) and Hennig-Schmidt and Wiesen (2014) use passive real patients as receivers of the health benefits created by subjects in the role of physicians by transferring the monetary value to a charity caring for ophthalmic patients. This procedure increases the salience of the professional norm which could be an explanation for the different findings (Kesternich et al., 2015). Given our primary research question, the creation of real health benefits outside the laboratory, however, was not possible to implement.

Overall, our results confirm that the level of trust in a health care credence goods market with medical students in the role of physicians compared to a neutrally framed credence goods market with standard student subjects in the role of experts is higher, even though the level of trustworthiness does not increase significantly.

\section{References}

Ahlert, M., Felder, S., Vogt, B., 2012. Which Patients Do I Treat? An Experimental Study with Economists and Physicians. Health Econ Rev, 2(1), 1.

Ahlert, M., Funke, K., Schwettmann, L., 2013. Thresholds, Productivity, and Context: An Experimental Study on Determinants of Distributive Behaviour. Social Choice and Welfare, 40(4), 957-984.

Angerer, S., Glätzle-Rüetzler, D., Waibel, C., 2021. Monitoring Institutions in Health Care Markets: Experimental Evidence. Health Economics (forthcoming).

Balafoutas, L., Beck, A., Kerschbamer, R., Sutter, M., 2013. What Drives Taxi Drivers? A Field Experiment on Fraud in a Market for Credence Goods. The Review of Economic Studies, 80(3), 876-891.

Balafoutas, L., Kerschbamer, R., 2020. Credence Goods in the Literature: What the Past Fifteen Years Have Taught Us About Fraud, Incentives, and the Role of Institutions. Journal of Behavioral and Experimental Finance, 26, 100285.

Balafoutas, L., Kerschbamer, R., Sutter, M., 2017. Second-Degree Moral Hazard in a Real-World Credence Goods Market. Economic Journal, 127(599), 1-18.

Beck, A., Kerschbamer, R., Qiu, J., Sutter, M., 2014. Car Mechanics in the Lab-Investigating the Behavior of Real Experts on Experimental Markets for Credence Goods. Journal of Economic Behavior \& Organization, 108, 166-173.

Bock, O., Baetge, I., Nicklisch, A., 2014, Hroot: Hamburg Registration and Organization Online Tool, vol. 71.

Brenan, M., 2018. Nurses Again Outpace Other Professions for Honesty, Ethics. https://news.gallup.com/poll/245597/nurses-again-outpace-professions-honesty-ethics.aspx. Accessed March 31, 2020.

Brosig-Koch, J., Hennig-Schmidt, H., Kairies-Schwarz, N., Wiesen, D., 2016. Using Artefactual Field and Lab Experiments to Investigate How Fee-for-Service and Capitation Affect Medical Service Provision. Journal of Economic Behavior \& Organization, 131, 17-23.

Buckley, N., Cuff, K., Hurley, J., Mestelman, S., Thomas, S., Cameron, D., 2016. Should I Stay or Should I Go? Exit Options within Mixed Systems of Public and Private Health Care Finance. Journal of Economic Behavior \& Organization, 131, 62-77.

Camerer, C.F., Dreber, A., Forsell, E., Ho, T.-H., Huber, J., Johannesson, M., Kirchler, M., Almenberg, J., Altmejd, A., Chan, T., Heikensten, E., Holzmeister, F., Imai, T., Isaksson, S., Nave, G., Pfeiffer, T., Razen, M., Wu, H., 2016. Evaluating Replicability of Laboratory Experiments in Economics. Science, 351(6280), 1433. 
Chaudhuri, A., Li, Y., Paichayontvijit, T., 2016. What's in a Frame? Goal Framing, Trust and Reciprocity. Journal of Economic Psychology, 57, 117-135.

Clemens, J., Gottlieb, J.D., 2014. Do Physicians' Financial Incentives Affect Medical Treatment and Patient Health? American Economic Review, 104(4), 1320-1349.

Cookson, R., 2000. Framing Effects in Public Goods Experiments. Experimental Economics, 3(1), 5579.

Cox, J.C., Green, E.P., Hennig-Schmidt, H., 2016. Experimental and Behavioral Economics of Healthcare. Journal of Economic Behavior \& Organization, 131, A1-A4.

Cutler, D.M., 1995. The Incidence of Adverse Medical Outcomes under Prospective Payment. Econometrica, 63(1), 29-50.

Darby, M.R., Karni, E., 1973. Free Competition and the Optimal Amount of Fraud. Journal of Law \& Economics, 16(1), 67-88.

Dufwenberg, M., Gächter, S., Hennig-Schmidt, H., 2011. The Framing of Games and the Psychology of Play. Games and Economic Behavior, 73(2), 459-478.

Dulleck, U., Kerschbamer, R., 2006. On Doctors, Mechanics, and Computer Specialists: The Economics of Credence Goods. Journal of Economic Literature, 44(1), 5-42.

Dulleck, U., Kerschbamer, R., Sutter, M., 2011. The Economics of Credence Goods: An Experiment on the Role of Liability, Verifiability, Reputation, and Competition. American Economic Review, 101(2), 526-555.

Fischbacher, U., 2007. Z-Tree: Zurich Toolbox for Ready-Made Economic Experiments. Experimental Economics, 10(2), 171-178.

Goerg, S.J., Walkowitz, G., 2010. On the Prevalence of Framing Effects across Subject-Pools in a Two-Person Cooperation Game. Journal of Economic Psychology, 31(6), 849-859.

Gottschalk, F., Mimra, W., Waibel, C., 2020. Health Services as Credence Goods: A Field Experiment. The Economic Journal, 130(629), 1346-1383.

Hennig-Schmidt, H., Jurges, H., Wiesen, D., 2019. Dishonesty in Health Care Practice: A Behavioral Experiment on Upcoding in Neonatology. Health Economics, 28(3), 319-338.

Hennig-Schmidt, H., Wiesen, D., 2014. Other-Regarding Behavior and Motivation in Health Care Provision: An Experiment with Medical and Non-Medical Students. Soc Sci Med, 108, 156165.

Huck, S., Lünser, G., Spitzer, F., Tyran, J.-R., 2016. Medical Insurance and Free Choice of Physician Shape Patient Overtreatment: A Laboratory Experiment. Journal of Economic Behavior \& Organization, 131, 78-105.

Jürges, H., Köberlein, J., 2015. What Explains Drg Upcoding in Neonatology? The Roles of Financial Incentives and Infant Health. Journal of Health Economics, 43, 13-26.

Kairies-Schwarz, N., Kokot, J., Vomhof, M., Weßling, J., 2017. Health Insurance Choice and Risk Preferences under Cumulative Prospect Theory - an Experiment. Journal of Economic Behavior \& Organization, 137, 374-397.

Kerschbamer, R., Neururer, D., Sutter, M., 2016. Insurance Coverage of Customers Induces Dishonesty of Sellers in Markets for Credence Goods. Proceedings of the National Academy of Sciences, 113(27), 7454-7458.

Kesternich, I., Schumacher, H., Winter, J., 2015. Professional Norms and Physician Behavior: Homo Oeconomicus or Homo Hippocraticus? Journal of Public Economics, 131, 1-11.

Maynard, A., Bloor, K., 2003. Trust and Performance Management in the Medical Marketplace. J R Soc Med, 96(11), 532-539.

Mimra, W., Rasch, A., Waibel, C., 2016a. Price Competition and Reputation in Credence Goods Markets: Experimental Evidence. Games and Economic Behavior, 100, 337-352.

Mimra, W., Rasch, A., Waibel, C., 2016b. Second Opinions in Markets for Expert Services: Experimental Evidence. Journal of Economic Behavior \& Organization, 131, 106-125.

Nelson, P., 1970. Information and Consumer Behavior. Journal of Political Economy, 78(2), 311-329.

Pasero, C., McCaffery, M., 2001. Pain Control: The Undertreatment of Pain. The American Journal of Nursing, 101(11), 62-65.

Piette, J.D., Heisler, M., Krein, S., Kerr, E.A., 2005. The Role of Patient-Physician Trust in Moderating Medication Nonadherence Due to Cost Pressures. Archives of internal medicine, 165(15), 1749-1755. 
Rasch, A., Waibel, C., 2018. What Drives Fraud in a Credence Goods Market? - Evidence from a Field Study. Oxford Bulletin of Economics and Statistics, 80(3), 605-624.

Reif, S., Hafner, L., Seebauer, M., 2020. Physician Behavior under Prospective Payment SchemesEvidence from Artefactual Field and Lab Experiments. International Journal of Environmental Research and Public Health, 17(15), 5540.

Schneider, H.S., 2012. Agency Problems and Reputation in Expert Services: Evidence from Auto Repair. The Journal of Industrial Economics, 60(3), 406-433.

Tversky, A., Kahneman, D., 1981. The Framing of Decisions and the Psychology of Choice. Science, 211(4481), 453.

Wang, J., Iversen, T., Hennig-Schmidt, H., Godager, G., 2020. Are Patient-Regarding Preferences Stable? Evidence from a Laboratory Experiment with Physicians and Medical Students from Different Countries. European Economic Review, 125, 103411. 


\section{Appendix}

\section{Additional Figures and Tables}

Figure A1: Extensive Form of the Stage Game

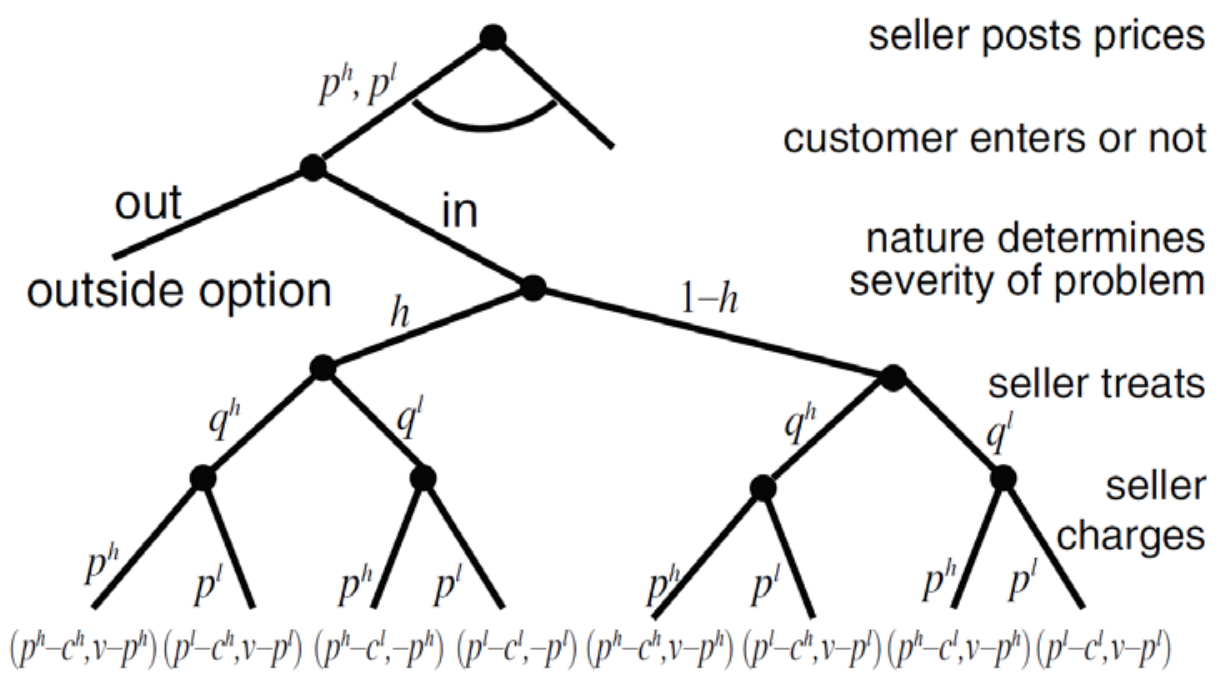

Source: Dulleck et al. (2011) 
Table A1: Descriptive statistics subject pool

\begin{tabular}{lcccc}
\hline & \multicolumn{2}{c}{ HF } & \multicolumn{2}{c}{ HF\&MS } \\
& $\begin{array}{c}\text { Non-medical } \\
\text { students } \\
\text { (physician role) }\end{array}$ & $\begin{array}{c}\text { Non-medical } \\
\text { students } \\
\text { (patient role) }\end{array}$ & $\begin{array}{c}\text { Medical } \\
\text { students } \\
\text { (physician role) }\end{array}$ & $\begin{array}{c}\text { Non-medical } \\
\text { students } \\
\text { (patient role) }\end{array}$ \\
\hline Male (=1) & $61 \%$ & $50 \%$ & $35 \%$ & $45 \%$ \\
Age in years & $22.89(3.21)$ & $23.08(3.55)$ & $23.53(3.19)$ & $23.7(6.63)$ \\
Study progress & $3.64(2.17)$ & $3.58(2.71)$ & $6.25(3.18)$ & $3.95(3.06)$ \\
\hline Note: Information on background characteristics of student subjects in condition $\boldsymbol{B}$ is not available
\end{tabular}


Table A2: Random effects panel probit / OLS for each condition separately

\begin{tabular}{|c|c|c|c|c|}
\hline VARIABLES & $\begin{array}{c}(1) \\
\mathrm{OC}^{1, \mathrm{a}}\end{array}$ & $\begin{array}{c}(2) \\
\mathrm{UT}^{2, \mathrm{a}}\end{array}$ & $\begin{array}{c}\text { (3) } \\
\mathrm{INT}^{3, \mathrm{a}}\end{array}$ & $\begin{array}{c}(4) \\
\mathrm{EFF}^{4, \mathrm{~b}}\end{array}$ \\
\hline \multicolumn{5}{|l|}{ Condition $\boldsymbol{B}$} \\
\hline \multirow[t]{2}{*}{ Period } & $0.138 *$ & $0.126 * * *$ & $-0.070 * * *$ & 0.008 \\
\hline & $(0.074)$ & $(0.039)$ & $(0.016)$ & $(0.015)$ \\
\hline \multirow[t]{2}{*}{ Constant } & 0.704 & $-0.740^{*}$ & $0.420 * * *$ & $-0.520 * * *$ \\
\hline & $(0.527)$ & $(0.437)$ & $(0.112)$ & $(0.198)$ \\
\hline Observations & 173 & 172 & 768 & 768 \\
\hline Number of subjectid & 46 & 47 & 48 & 48 \\
\hline \multicolumn{5}{|l|}{ Condition $\boldsymbol{H F}$} \\
\hline \multirow[t]{2}{*}{ Period } & 0.226 & 0.064 & $-0.052 * * *$ & 0.004 \\
\hline & $(0.527)$ & $(0.041)$ & $(0.011)$ & $(0.013)$ \\
\hline \multirow[t]{2}{*}{ Constant } & 7.100 & -0.548 & $0.671^{* * *}$ & $-0.435^{*}$ \\
\hline & (61.713) & $(0.901)$ & $(0.205)$ & $(0.246)$ \\
\hline Observations & 177 & 152 & 576 & 576 \\
\hline Number of subjectid & 35 & 35 & 36 & 36 \\
\hline \multicolumn{5}{|l|}{ Condition $\boldsymbol{H F} \& \boldsymbol{M S}$} \\
\hline \multirow[t]{2}{*}{ Period } & $0.091^{* * *}$ & $0.136 * * *$ & $-0.040 * *$ & -0.010 \\
\hline & $(0.035)$ & $(0.046)$ & $(0.018)$ & $(0.023)$ \\
\hline \multirow[t]{2}{*}{ Constant } & 0.646 & -2.093 & 0.823 & -0.111 \\
\hline & $(0.667)$ & (5.467) & $(0.113)$ & $(0.244)$ \\
\hline Observations & 228 & 187 & 640 & 640 \\
\hline Number of subjectid & 40 & 39 & 40 & 40 \\
\hline \multicolumn{5}{|c|}{ Notes: $* * * \mathrm{p}<0.01, * * \mathrm{p}<0.05, * \mathrm{p}<0.1$} \\
\hline \multirow{3}{*}{\multicolumn{5}{|c|}{$\begin{array}{l}{ }_{1} \text { Overcharching (OC): seller provides } q_{l} \text {, but charges } p_{h} \text { (with } p_{h}>p_{l} \text { and consumer needing } q_{l} \text { ) } \\
{ }^{2} \text { Undertreatment (UT): consumer needs } q_{h} \text {, but the seller provides } q_{l} \\
{ }^{3} \text { Relative frequency of market interaction (INT) }\end{array}$}} \\
\hline & & & & \\
\hline & & & & \\
\hline \multicolumn{5}{|c|}{${ }^{4}$ Market efficiency (EFF) calculated as $\frac{\text { actual average profit }}{\text { maximum possible profit }}$} \\
\hline
\end{tabular}




\section{Experimental Instructions (condition HF and condition HF\&MS in italics)}

\section{Dear participants,}

Welcome to today's experiment!

Please read the instructions for the experiment carefully. All statements in the instructions are true. Your payoff at the end of the experiment depends on how well you have understood the instructions. All data gathered during the experiment will be treated confidentially and evaluated anonymously.

We ask you to remove all items, including other reading materials and writing utensils from the table, and switch off your mobile phone, as well as any other electronic devices. If you have a question, raise your hand and one of the experimenters will come to you to answer your question privately.

All personal designations in this experiment refer equally to men and women.

Thank you very much for your participation in today's experiment.

\section{Instructions for the experiment}

Thank you very much for your participation in the experiment. Please do not speak to other participants until the end of the experiment.

\section{2 roles and 16 rounds}

This experiment consists of $\mathbf{1 6}$ rounds, each with the same sequence of decisions. The sequence of decisions is explained in detail below.

There are 2 roles in the experiment: Doctor and patient. At the beginning of the experiment, you will be randomly assigned one of these roles and keep it for the whole experiment. On the first screen of the experiment, you will see which role you have. This role remains the same for all 16 rounds. (HF\&MS: All participants with the participant numbers 1-4, 9-12, and 17-20 are in the role of doctors. All other participants (participant numbers 5-8, 13-16, and 21-24) are in the role of patients). Participants in the role of doctors are medical students, whereas participants in the role of patients are non-medical students (all fields of study except medicine).

A doctor always interacts with a patient. However, the pairs change after each round. This means that you interact with a new player (of the other role) in each round.

All experiment participants receive the same information regarding the rules of the game, including costs and payoffs to both players.

\section{Overview of the decisions in a round}

Each round consists of a maximum of 4 decisions, which are made successively. Decisions 1, 3, and 4 are made by the doctor; decision 2 is made by the patient. 


\section{The sequence of decisions in every round (concise)}

1. The doctor chooses prices for the minor and the major treatment.

2. The patient learns the prices chosen by the doctor. Then the patient decides if he/she wants to visit (interact with) this doctor. If not, this round ends.

If yes ...

3. The doctor (but not the patient) receives information about whether the patient has a minor or a major illness. Then the doctor chooses a minor treatment or a major treatment.

4. The doctor asks the patient to pay the price for one of the two treatments (minor or major) set in decision 1 . The price charged need not be the same as the price for the treatment chosen in decision 3 but maybe the price of the other treatment.

\section{Detailed presentation of decisions and their consequences in terms of payoffs}

\section{Decision 1}

In decision 3 the doctor chooses between two treatments, a minor treatment, and a major treatment.

The minor treatment costs the doctor 2 points (= experimental currency unit)

The major treatment costs the doctor 6 points.

For both treatments, the doctor charges prices to the patient. In decision $\mathbf{1}$ the doctor has to set prices for both treatments. Only (strictly) positive prices in full points from 1 point to a maximum of 11 points are possible. I.e. the allowed prices are 1, 2, 3, 4, 5, 6, 7, 8, 9, 10, or 11 .

Please note that the price for the minor treatment may not exceed the price for the major treatment.

\section{Decision 2}

The patient learns the prices set by the doctor in decision 1 . Then the patient decides if he/she wants to see (interact with) this doctor.

If yes, this means that the doctor in decisions 3 and 4 chooses a treatment and charges a price for it (see below). However, the patient will not be able to observe which treatment the doctor chooses.

If no, this round ends and both players receive a payoff of 1.6 points for this round. 
Before decision 3 (if the patient has chosen "yes" in decision 2) an illness is randomly determined for the patient. The patient may have 2 types of illnesses: A minor illness or a major illness. The illness is randomly determined every new round.

The patient suffers with a $\mathbf{5 0 \%}$ chance from a minor illness and with a $\mathbf{5 0 \%}$ chance from a major illness. Imagine a coin toss in each round - if the coin shows "head", then the patient suffers from a minor illness, if it shows "tails", the patient suffers from a major illness.

The doctor learns about the patient's illness before making his/her decision 3. Then the doctor chooses a treatment, either the minor treatment or the major treatment.

The treatment cures the patient's illness under the following conditions:

a) The patient has a minor illness and the doctor chooses either the minor treatment or the major treatment.

b) The patient has a major illness and the doctor chooses the major treatment.

The treatment does not cure the disease if the patient has a major illness, but the doctor chooses the minor treatment.

The patient receives 10 points if the treatment chosen by the doctor cures his/her illness. The patient receives $\mathbf{0}$ points if the treatment chosen by the doctor does not cure his/her illness.

At no time is the patient informed on the computer screen whether he/she has had a minor illness or a major illness in any round or which treatment the doctor has chosen.

\section{Decision 4}

The doctor asks the patient to pay the price, set in decision 1 , for one of the two treatments. The asked price does not have to be equal to the price of the treatment chosen in decision 3 but can be the price of the other treatment.

\section{Payoffs}

If the patient in decision 2 ends the round (decision "No" of the patient), then both players receive $\mathbf{1 . 6}$ points in this round.

Otherwise (decision "Yes" of the patient) the payoffs are as follows:

The doctor receives the price (in points) chosen in decision 4 minus the costs for the treatment chosen in decision 3.

For the patient, the payoff depends on whether the treatment chosen by the doctor in decision 3 has cured the patient's illness.

a) The doctor's treatment cured the illness. The patient receives $\mathbf{1 0}$ points minus the price of the treatment chosen in decision 4.

b) The doctor's treatment did not cure the illness. The patient must pay the price chosen in decision 4.

At the beginning of the experiment, you will receive an initial endowment of 6 points. Additionally, you will receive another $\mathbf{1 0}$ points for answering the control questions. From this initial endowment, 
you can pay for possible losses in individual rounds. Losses can also be compensated by winnings from other rounds. If you have made a total loss at the end of the experiment, you must pay this loss to the experimenter. By participating in the experiment, you agree to this condition. Please note, however, that there is always a way to avoid losses with certainty in this experiment.

For the payoff, the initial endowment and the winnings of all rounds are added together and converted into cash at the end of the experiment using the following exchange rate:

\section{1 point $=25$ Euro-Cent}

(i.e. 4 points $=1$ euro). 


\section{Control Questions (condition HF and condition HF\&MS)}

It is important to make sure that all participants have fully understood the experiment. Should something have remained unclear, please ask the experimenter. You will receive 10 points $(=2.5$ Euro) for answering the questions correctly. Please answer the following questions:

\begin{tabular}{|c|c|}
\hline Question & $\begin{array}{l}\text { Correct } \\
\text { Answer }\end{array}$ \\
\hline 1. How many decisions does a physician maximally make per period? & 3 \\
\hline 2. How many decisions does a patient make per period? & 1 \\
\hline Assess whether the statements below are true or false. & \\
\hline $\begin{array}{l}\text { 3. "The price for the minor treatment can be higher than the price for the major } \\
\text { treatment." }\end{array}$ & $\mathrm{F}$ \\
\hline $\begin{array}{l}\text { 4. "If the patient in decision } 2 \text { chooses "No", then both players receive } 1.6 \text { points in } \\
\text { this round." }\end{array}$ & $\mathrm{T}$ \\
\hline $\begin{array}{l}\text { 5. "The patient is shown on a computer screen which illness he suffers from in a } \\
\text { particular round." }\end{array}$ & $\mathrm{F}$ \\
\hline $\begin{array}{l}\text { 6. "If the physician chooses a treatment that cures the illness, the total payoff for the } \\
\text { patient in that round is exactly } 10 \text { points." }\end{array}$ & $\mathrm{F}$ \\
\hline $\begin{array}{l}\text { 7. "The maximum payoff for a patient in a round is } 9 \text { points, namely if the physician } \\
\text { chooses a treatment that cures the illness and charges a price of } 1 \text { point." }\end{array}$ & $\mathrm{T}$ \\
\hline 8. "The initial endowment of 6 points is worth 1.5 euros." & $\mathrm{T}$ \\
\hline $\begin{array}{l}\text { Please calculate the payoffs (in points) for the patient and the physician in the } \\
\text { following examples: }\end{array}$ & \\
\hline $\begin{array}{l}\text { 9. The physician sets the following prices: the price for the minor treatment }=2 \\
\text { points, the price for the major treatment = } 8 \text { points. } \\
\text { The patient chooses "No" in decision } 2 \text {. }\end{array}$ & $\begin{array}{l}\text { Patient: } 1.6 \\
\text { Physician: } \\
1.6\end{array}$ \\
\hline $\begin{array}{l}\text { 10. The physician sets the following prices: the price for the minor treatment }=3 \\
\text { points, the price for the major treatment }=7 \text { points. } \\
\text { The patient chooses "Yes" in decision } 2 . \\
\text { The patient suffers from a major illness. } \\
\text { The physician chooses the major treatment and charges the price for the major } \\
\text { treatment. }\end{array}$ & $\begin{array}{l}\text { Patient: } 3 \\
\text { Physician: } 1\end{array}$ \\
\hline $\begin{array}{l}\text { 11. The physician sets the following prices: the price for the minor treatment }=7 \\
\text { points, the price for the major treatment }=9 \text { points. } \\
\text { The patient chooses "Yes" in decision } 2 . \\
\text { The patient suffers from a mild illness. } \\
\text { The physician chooses the mild treatment and charges the price for the mild } \\
\text { treatment. }\end{array}$ & $\begin{array}{l}\text { Patient: } 3 \\
\text { Physician: } 5\end{array}$ \\
\hline
\end{tabular}

The experiment continues as soon as all participants have answered the questions correctly. 
University of Innsbruck - Working Papers in Economics and Statistics

Recent Papers can be accessed on the following webpage:

https://www.uibk.ac.at/eeecon/wopec/

2021-13 Silvia Angerer, Daniela Glätzle-Rützler, Christian Waibel: Trust in health care credence goods: Experimental evidence on framing andsubject pool effects

2021-12 Rene Schwaiger, Laura Hueber: Do MTurkers Exhibit Myopic Loss Aversion?

2021-11 Felix Holzmeister, Christoph Huber, Stefan Palan: A Critical Perspective on the Conceptualization of Risk in Behavioral and Experimental Finance

2021-10 Michael Razen, Alexander Kupfer: Can increased tax transparency curb corporate tax avoidance?

2021-09 Changxia Ke, Florian Morath, Anthony Newell, Lionel Page: Too big to prevail: The paradox of power in coalition formation

2021-08 Marco Haan, Pim Heijnen, Martin Obradovits: Competition with List Prices

2021-07 Martin Dufwenberg, Olof Johansson-Stenman, Michael Kirchler, Florian Lindner, Rene Schwaiger: Mean Markets or Kind Commerce?

2021-06 Christoph Huber, Jürgen Huber, and Michael Kirchler: Volatility Shocks and Investment Behavior

2021-05 Max Breitenlechner, Georgios Georgiadis, Ben Schumann: What goes around comes around: How large are spillbacks from US monetary policy?

2021-04 Utz Weitzel, Michael Kirchler: The Banker's Oath And Financial Advice

2021-03 Martin Holmen, Felix Holzmeister, Michael Kirchler, Matthias Stefan, Erik Wengström: Economic Preferences and Personality Traits Among Finance Professionals and the General Population

2021-02 Christian König-Kersting: On the Robustness of Social Norm Elicitation

2021-01 Laura Hueber, Rene Schwaiger: Debiasing Through Experience Sampling: The Case of Myopic Loss Aversion.

2020-34 Kai A. Konrad, Florian Morath: The Volunteer's Dilemma in Finite Populations

2020-33 Katharina Momsen, Markus Ohndorf: Expressive Voting vs. Self-Serving Ignorance

2020-32 Silvia Angerer, Daniela Glätzle-Rützler, Christian Waibel: Monitoring institutions in health care markets: Experimental evidence 
2020-31 Jana Friedrichsen, Katharina Momsen, Stefano Piasenti: Ignorance, Intention and Stochastic Outcomes

2020-30 Esther Blanco, Alexandra Baier, Felix Holzmeister, Tarek Jaber-Lopez, Natalie Struwe: Substitution of social concerns under the Covid-19 pandemic

2020-29 Andreas Hackethal, Michael Kirchler, Christine Laudenbach, Michael Razen, Annika Weber: On the (ir)relevance of monetary incentives in risk preference elicitation experiments

2020-28 Andrej Gill, Matthias Heinz, Heiner Schumacher, Matthias Sutter: Trustworthiness in the Financial Industry

2020-27 Matthias Sutter, Michael Weyland, Anna Untertrifaller, Manuel Froitzheim: Financial literacy, risk and time preferences - Results from a randomized educational intervention

2020-26 Rene Schwaiger, Jürgen Huber, Michael Kirchler, Daniel Kleinlercher, Utz Weitzel: Unequal Opportunities, Social Groups, and Redistribution

2020-25 Roman Inderst, Martin Obradovits: Competitive Strategies when Consumers are Relative Thinkers: Implications for Pricing, Promotions, and Product Choice

2020-24 Martin Obradovits, Philipp Plaickner: Price-Directed Search and Collusion

2020-23 Helena Fornwagner, Oliver P. Hauser: Climate action for (my) children

2020-22 Esther Blanco, Natalie Struwe, James M. Walker: Incentivizing public good provision through outsider transfers: experimental evidence on sharing rules and additionality requirements

2020-21 Loukas Balafoutas, Helena Fornwagner, Rudolf Kerschbamer, Matthias Sutter, Maryna Tverdostup: Diagnostic Uncertainty and Insurance Coverage in Credence Goods Markets

2020-20 Anna Ulrichshofer, Markus Walzl: Customer Disputes, Misconduct, and Reputation Building in the Market for Financial Advice

2020-19 Anna Ulrichshofer, Markus Walzl: Social Comparison and Optimal Contracts in the Competition for Managerial Talent

2020-18 Martin Obradovits, Philipp Plaickner: Searching for Treatment

2020-17 Jun Honda: The Gender-Punishment Gap revisited

2020-16 Jun Honda: The Relation between Rankings and Risk-Taking in the Labor Market for Financial Advice

2020-15 Christina Bannier, Eberhard Feess,Natalie Packham, Markus Walzl: Differentiation and Risk-Aversion in Imperfectly Competitive Labor Markets 
2020-14 Felix Holzmeister, Rudolf Kerschbamer: oTree: The Equality Equivalence Test

2020-13 Parampreet Christopher Bindra, Graeme Pearce: The effect of priming on fraud: Evidence from a natural field experiment

2020-12 Alessandro De Chiara, Marco A. Schwarz: A Dynamic Theory of Regulatory Capture

2020-11 Christoph Huber, Jürgen Huber, Michael Kirchler: Market shocks and professionals' investment behavior - Evidence from the COVID-19 crash

2020-10 Elisabeth Gsottbauer, Daniel Müller, Samuel Müller, Stefan T. Trautmann, Galina Zudenkova: Social class and (un)ethical behavior: Causal versus correlational evidence

2020-09 Parampreet Christopher Bindra, Rudolf Kerschbamer, Daniel Neururer, Matthias Sutter: Reveal it or conceal it: On the value of second opinions in a low-entrybarriers credence goods market

2020-08 Robert Steiger, Eva Posch, Gottfried Tappeiner, Janette Walde: Effects of climate change on tourism demand considering individual seasonal preferences

2020-07 Fang Liu, Alexander Rasch, Marco A. Schwarz, Christian Waibel: The role of diagnostic ability in markets for expert services

2020-06 Matthias Stefan, Jürgen Huber, Michael Kirchler, Matthias Sutter, Markus Walzl: Monetary and Social Incentives in Multi-Tasking: The Ranking Substitution Effect

2020-05 Michael Razen, Jürgen Huber, Laura Hueber, Michael Kirchler, Matthias Stefan: Financial Literacy, Economic Preferences, and Adolescents' Field Behavior

2020-04 Christian König-Kersting, Johannes Lohse, Anna Louisa Merkel: Active and Passive Risk-Taking

2020-03 Christoph Huber, Jürgen Huber: Bad bankers no more? Truth-telling and (dis)honesty in the finance industry

2020-02 Dietmar Fehr, Daniel Müller, Marcel Preuss: Social Mobility Perceptions and Inequality Acceptance

2020-01 Loukas Balafoutas, Rudolf Kerschbamer: Credence goods in the literature: What the past fifteen years have taught us about fraud, incentives, and the role of institutions 


\title{
University of Innsbruck
}

\section{Working Papers in Economics and Statistics}

$2021-13$

Silvia Angerer, Daniela Glätzle-Rützler, Christian Waibel

Trust in health care credence goods:Experimental evidence on framing andsubject pool effects

\begin{abstract}
Credence goods markets are characterized by asymmetric information concerning the needed and/or provided quality between experts and consumers. The functioning of the market heavily relies on trust on the side of the consumer as well as trustworthiness on the side of the expert. However, a great amount of empirical and experimental papers document for a range of different credence goods markets the existence of over-, undertreatment, and overcharging. In this paper, we study two determinants of trust and trustworthiness in experimental credence goods markets, namely the effect of a health frame (versus a neutral frame) as well as the identity of the expert (being either a standard student subject or a prospective physician). Our results reveal that the identity in combination with a health frame has a significant impact on the level of trust shown by a higher willingness of consumers (patients) to enter the market. Trustworthiness, as measured by the provision and charging behavior of experts, however, is not significantly influenced by the health care framing, nor by the subject pool.
\end{abstract}

ISSN 1993-4378 (Print)

ISSN 1993-6885 (Online) 